\title{
Analytical Determination of Conditions of Wagon Rolling Down Marshalling Hump Profiles
}

\author{
Khabibulla Turanov, Andrey Gordiienko \\ Urals State University of Railway Transport (USURT), Ekaterinburg, Russia \\ Email: khturanov@yandex.ru
}

Received 17 September 2015; accepted 5 October 2015; published 8 October 2015

Copyright (C) 2015 by authors and OALib.

This work is licensed under the Creative Commons Attribution International License (CC BY). http://creativecommons.org/licenses/by/4.0/

(c) (i) Open Access

\begin{abstract}
The article contains a model of wagon rolling down the hump profiles. It deals with motive and resistance forces. These forces made it possible to mathematically describe geometrical parameters of hump profile and kinematical characteristics of wagon movement depending on time. The conditions have been formulated, which makes the wagon movement down various marshalling hump profile sections possible. These conditions enable slowdown of the wagon as it moves from one hump profile element to the other until it stops in the hump-yard.
\end{abstract}

\section{Keywords}

Marshalling Hump, Sliding Friction, Sliding with Rolling, Rolling Friction, Transverse Transferring Inertia Force, Aerodynamic Resistance Force, Reducing Force System to a Given Point, Coulomb Law, Retarded Heaviside Functions

Subject Area: Mechanical Engineering

\section{Introduction}

In [1] on the basis of critical analysis of the known works [2] [3] where the dynamic model of wagon rolling down hasn't been built quite correctly, there has been demonstration of the account taken in moments of friction of wheels against rail threads and in box unit bearing in leading and rear trucks with their subsequent replacement by symbolic sliding friction. It has been observed that if the active force in the form of gravity force projection and aerodynamic resistance force toward the direction of wagon (or cut) rolling acting upon the wagon are larger than the ultimate friction force simultaneously with wheel rolling there can be also wheel sliding down rail threads. An analytical formula for finding the remainder of motive forces and all resistance forces under wheel rolling with sliding has been derived. The usage of principle of momentum of a material point [4] [5]

How to cite this paper: Turanov, K. and Gordiienko, A. (2015) Analytical Determination of Conditions of Wagon Rolling Down Marshalling Hump Profiles. Open Access Library Journal, 2: e1912. http://dx.doi.org/10.4236/oalib.1101912 
made it possible to construct a mathematical model for finding the speed of a single wagon (or a cut) on the first profile hump section. It has been noted that the usage of principle momentum of a material point for finding the time of wagon rolling down the hump can be applied only when the wagon final speed is known otherwise the problem solution in such a form will prove to be meaningless. Due to this fact, in [1] speed finding should be considered as separate task requiring its solution based on drawing of differential equation of the movement [6] [7].

In [2] on the assumption of uniformly accelerated wagon rolling down the hump, the formula for determining the braking force causing uniform wagon movement at constant speed has been found. As a result of analytical modeling of wagon movement on the section of the first braking position, various conditions which enable wagon movement on the first braking position section $\left(1^{\text {st }} \mathrm{BP}\right)$ at speed which is lower than the entrance speed have been formulated. There have been derived equations of wagon rolling speed and obtained final analytical formulas for finding the distance travelled, the movement time on the given length of the braking section making it possible the movement of a wagon (cut) with slowdown before switching area. Analytical formulas for determining braking distance have been obtained in a case when wagon motive forces are lower than the braking ones which may occur in case of non-observance of certain conditions.

In [6] [7] it has been noted that the development of theoretical fundamentals of calculation of wagon rolling by means of creating computational and constructing mathematical model on any hump section enabling the determination of rational geometrical parameters of hump profile and kinematic parameters of the wagon is a pressing problem of railway transport.

On this basis it should be observed that the determination of forces perceived by the wagon rolling down the hump profile is part of a still unsolved problem.

\section{Formulation of a Problem}

It is required to find all motive forces and resistance forces acting upon the wagon and emerging during its rolling down the hump profile because of the friction of wheels against rail threads, friction in bearings in box units and due to some other accidental forces with allowance made for the action upon the wagon (or the cut) of transverse transferring inertia force and head or/and fair wind.

\section{Methods of Solution}

Just as in [6] [7] we will consider the general case when the wagon is progressively rolling down the hump with a given initial speed $\bar{v}_{0}$ (normally $4 / 5 \mathrm{~km} / \mathrm{h}$ ). While rolling down the hump the wagon will experience mainly the action of external forces in the form of gravity force of wagon with cargo or without cargo- $\bar{G}$ and aerodynamic resistance force $\bar{F}_{r w}$ (where $\left.\bar{F}_{r w}=\left\{\bar{F}_{r w x}^{\prime}, \bar{F}_{r w y}^{\prime}\right\}\right)$ [8].

We assume that in case of absence of the action of aerodynamic resistance force from the wagon side face (i.e. under $F_{r w y}^{\prime}=0$ ) truck wheel pairs roll without sliding during wagon movement before and outside braking positions (BP). According to Poinsot theorem taken from kinematics [5], wheel pure rolling of a truck wheel pair (as moving centroid) down the rail threads (fixed centroid) accounts for the fact that their point of contact ( as contact of a circumference with a straight line) at the given time $t_{1}$, being their speed instant center (SIC) has the speed equal to zero.

Let us suppose that under changing climatic conditions during winter causing the change of air density followed by snow and hoarfrost, within bundle switching area and on sorting tracks, during wagon entrance on a side track through point switch, under the action of force $F_{r w y}^{\prime}$ and during wagon movement within braking positions wheel pairs roll down the rail threads with sliding.

We assume that during wagon passing along the length of hump and/or yard braking position (BP) truck wheel pairs move down the rail threads with sliding without rolling, but at the same time depending on the value of braking forces wheel sliding with rolling is not excluded.

\section{Man-Made Assumption}

Just as in [6] [7] we will consider the general case when the wagon is progressively rolling down the hump with a given initial speed $\bar{v}_{0}$ (normally $4 / 5 \mathrm{~km} / \mathrm{h}$ ). While rolling down the hump the wagon will experience mainly the action of external forces in the form of gravity force of wagon with cargo or without cargo $-\bar{G}$ and aero- 
dynamic resistance force $\bar{F}_{r w}$ (where $\left.\bar{F}_{r w}=\left\{\bar{F}_{r w x}^{\prime}, \bar{F}_{r w y}^{\prime}\right\}\right)$ [8].

We assume that in case of absence of the action of aerodynamic resistance force from the wagon side face (i.e. under $F_{r w y}^{\prime}=0$ ) truck wheel pairs roll without sliding during wagon movement before and outside braking positions (BP). According to Poinsot theorem taken from kinematics [5], wheel pure rolling of a truck wheel pair (as moving centroid) down the rail threads (fixed centroid) accounts for the fact that their point of contact (as contact of a circumference with a straight line) at the given time $t_{1}$, being their speed instant center (SIC) has the speed equal to zero.

Let us suppose that under changing climatic conditions during winter causing the change of air density followed by snow and hoarfrost, within bundle switching area and on sorting tracks, during wagon entrance on a side track through point switch, under the action of force $F_{r w y}^{\prime}$ and during wagon movement within braking positions wheel pairs roll down the rail threads with sliding.

We assume that during wagon passing along the length of hump and/or yard braking position (BP) truck wheel pairs move down the rail threads with sliding without rolling, but at the same time depending on the value of braking forces wheel sliding with rolling is not excluded.

\section{Results of Analytical Solution Problems}

As in [6] [7], for the simplified computational model of wagon rolling down the hump taking into account rolling friction (pure rolling) we will take the model presented in Figure 1.

The forces of wagon (or a cut) wheel friction against the rail threads in the absence of defects in rolling bearings of box units come down to the forces of rolling friction the basic moment of which can be taken to be equal to $M^{(e)}=f_{r f} F_{z}$, where $f_{r f}$ is a rolling friction coefficient, $\mathrm{m}$; as this coefficient is equipotent to the arm of couple of rolling friction (wheel down the rail $f_{r f}=5 \times 10^{-6}$, hardened steel on steel $f_{r f}=1 \times 10^{-6}$ ); $F_{z}$ is the sum of projections of all active forces onto the vertical axis falling at each box unit according to the technology of cargo mass center location in relation to axes of wagon crossing [6]:

$$
F_{z}=G \cos \psi_{0,50}+F_{r w x}^{\prime} \sin \psi_{0,50} .
$$

For the wheel pair of the wagon rolling down the hump up to the first braking position $\left(1^{\text {st }} \mathrm{BP}\right)$ due to the fact that there is always observed the condition $\bar{F}=G_{x} \geq \bar{F}_{f r}$, i.e. $F>\left(f_{f r} / r_{w}\right) F_{z}$ (where $G_{x}=G \sin \psi_{0,50} G_{x}=G \sin \psi_{0,50}$ is projection of gravity force of a wagon with cargo upon axis $O x, \mathrm{kN} ; r_{w}$ is wheel radius equal for a freight car to $0.475 \mathrm{~m}$ ). Here the relation $f_{f r} / r_{w}$ for the majority of materials is smaller than friction coefficient of sliding $f$. The value $f$ between contacting wheel surfaces of freight cars and rail threads is taken to be 0.25 [2]. It is due to this difference (i.e. $f_{f r} / r_{w} \ll f$ ) that there occurs the excess of forces $\Delta F_{k, 50}=G \sin \psi_{0,50}-F_{f r}$ causing wagon movement under its rolling down the hump with acceleration. An exception to this rule may be wet weather when coefficient $f$ is reduced.

Hence, it is clear that rolling friction as the need arises can be replaced by symbolic sliding friction under pure rolling [6] [7].

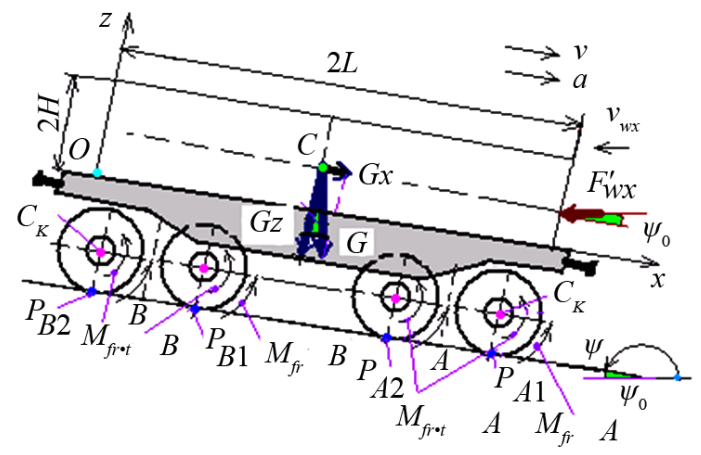

(a)

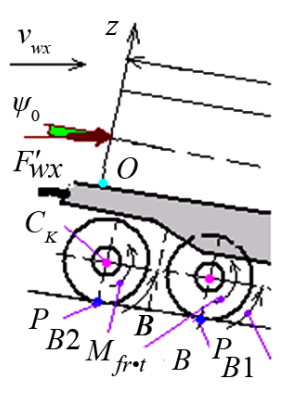

(b)

Figure 1. Simplified computational model of wagon rolling down the hump: (a) under head wind; (b) under fair wind. 


$$
F_{f r \cdot p r}=\frac{n_{w} f_{r f}}{r_{w}}\left(G \cos \psi_{0,50}+F_{r w x}^{\prime} \sin \psi_{0,50}\right),
$$

where $n_{w}$ is the number of wheels in trucks, item, $\left(n_{w}=8\right) ; f_{r f}$ is coefficient of rolling friction, $\mathrm{m}$, as this coefficient is equipotent to the arm of couple of rolling friction (wheel down the rail $f_{f r}=5 \times 10^{-6}$, hardened steel on steel $\left.f_{f r}=1 \times 10^{-6}\right), r_{w}$ is wheel radius equal for a freight car $0.475 \mathrm{~m}$.

On the mechanical system there also act internal forces in the form of rolling friction moments $M_{f r t A}$ $\left(M_{f r \cdot t A}=\left\{M_{f r \cdot t A 1}, M_{f r \cdot t A 2}, M_{f r \cdot t A^{\prime} 1}, M_{f r \cdot t A^{\prime} 2}\right\}\right)$ and $M_{f r \cdot t B}\left(M_{f r \cdot t B}=\left\{M_{f r \cdot t B 1}, M_{f r \cdot t B 2}, M_{f r \cdot t B^{\prime} 1}, M_{f r \cdot t B^{\prime} 2}\right\}\right)$ in bearings of box units in leading truck $A$ and rear truck $B$, at that $M_{\text {трп }}=M_{\text {трп } A}+M_{\text {трп } B \text {. }}$

In points of contact with rolling elements of inner diameter of bearing inner ring there emerge internal forces $N_{b r}$-normal component of bearing reaction and in the same point on the rolling element from the inner ring there acts reaction $N_{b}$ which is the same according to the module but opposite in direction. Here, just as above,

$$
N=\sum_{i=1}^{2}\left(N_{A i}+N_{A^{\prime} i}+N_{B i}+N_{B^{\prime} i}\right)
$$

( $i$ is the number of wheels in one truck axis $(i=2)$ );

$$
\bar{F}_{f r}=\bar{F}_{f r \cdot A}+\bar{F}_{f r \cdot A^{\prime}}+\bar{F}_{f r \cdot B}+\bar{F}_{f r \cdot B^{\prime}}+\bar{F}_{f r \cdot A W}+\bar{F}_{f r \cdot A^{\prime} W}+\bar{F}_{f r \cdot B W}+\bar{F}_{f r \cdot B^{\prime} W} .
$$

The moment of rolling friction in bearings of box units of leading and rear wagon trucks

$$
M_{f r b}=n_{b} f_{f r 0} N_{b}
$$

where $n_{b}=8$ is the number of box units in trucks, item; $f_{f r 0}$ is coefficient of friction of rolling elements down bearing rings (normally taken to be $0.001 \times 10^{-3}$ ), $\mathrm{m} ; N_{b}$ is normal reaction falling on two cylindrical roller bearings, or the force acting upon the most loaded rolling element and determined according to the formula, $\mathrm{kN}$ [6] [7]:

$$
N_{b}=\frac{k F_{z}}{n_{b} n_{f f r}},
$$

taking into account the fact that $n_{f f}$ is the total number of rolling elements, perceiving the load in each bearing, units; $k$ is constant coefficient which is taken according to the row lane and type of rolling bearings.

By analogy, (1) rolling friction can be replaced by symbolic sliding friction under pure rolling motion of rolling elements in bearings [6] [7]:

$$
F_{f r \cdot f f r}=\frac{n_{b b} f_{\kappa 0}}{r_{b}} N_{b},
$$

where $n_{b b}$ is the number of bearings in truck box units, item. $\left(n_{b b}=16\right) ; r_{b}$ is an outer radius of inner ring of roller bearing, $m$.

We rewrite the above formula taking into account (1a) and (2a):

$$
F_{f r \cdot r 0}=\frac{n_{b b} f_{k 0}}{r_{b}} \frac{k}{n_{b} n_{f f r}}\left(G \cos \psi_{0,50}+F_{r w x}^{\prime} \sin \psi_{0,50}\right) .
$$

Joining (1) and (3) wheel rolling friction can be replaced by symbolic sliding friction under pure rolling and rolling elements in bearing box units:

$$
F_{f r}^{r}=F_{f r \cdot p r}+F_{f r \cdot r 0}, \quad F_{f r}^{r}=f_{0}\left(G \cos \psi_{0,50}+F_{r w x}^{\prime} \sin \psi_{0,50}\right) .
$$

where $f_{0}$ is some symbolic (or modified) coefficient of sliding friction:

$$
f_{0}=\frac{n_{w} f_{f r}}{r_{w}}+\frac{n_{b b} f_{k 0}}{r_{b}} \frac{k}{n_{b} n_{f f r}} .
$$

In agreement with the above, all given constraint reaction are broken into normals $\bar{N}_{A}, \bar{N}_{B}, \bar{N}_{A^{\prime} H}, \bar{N}_{B^{\prime} H}$, 
$\bar{N}_{A^{\prime} W}, \bar{N}_{B^{\prime} W}$, and tangents $\bar{F}_{\tau A}, \bar{F}_{\tau B}, \bar{F}_{\tau A^{\prime} H}, \bar{F}_{\tau B^{\prime} H}, \bar{F}_{\tau A^{\prime} W}, \bar{F}_{\tau B^{\prime} W}$ constituents the way it is presented in [9].

In so doing, just as in [6] [7] allowance is made for the fact that $\bar{N}_{A}=\left\{\bar{N}_{A 1}, \bar{N}_{A 2}\right\}, \bar{N}_{A^{\prime}}=\left\{\bar{N}_{A^{\prime} 1}, \bar{N}_{A^{\prime} 2}\right\}$, $\bar{N}_{B}=\left\{\bar{N}_{B 1}, \bar{N}_{B 2}\right\}, \quad \bar{N}_{B^{\prime}}=\left\{\bar{N}_{B^{\prime} 1}, \bar{N}_{B^{\prime} 2}\right\} ; \quad \bar{F}_{\tau A}=\left\{F_{\tau A}^{\prime}, F_{\tau A}^{\prime \prime}\right\}, \bar{F}_{\tau A^{\prime}}=\left\{F_{\tau A^{\prime}}^{\prime}, F_{\tau A^{\prime}}^{\prime \prime}\right\}, \bar{F}_{\tau B}=\left\{F_{\tau B}^{\prime}, F_{\tau B}^{\prime \prime}\right\}$, $\bar{F}_{\tau B^{\prime}}=\left\{F_{\tau B^{\prime}}^{\prime}, F_{\tau B^{\prime}}^{\prime \prime}\right\}$.

It is also taken into account that the tangent constituents $\bar{F}_{\tau A}, \bar{F}_{\tau A^{\prime}}, \bar{F}_{\tau B}, \bar{F}_{\tau A}, \bar{F}_{\tau A^{\prime}}, \bar{F}_{\tau B}, \bar{F}_{\tau B^{\prime}}, \bar{F}_{\tau A^{\prime} W}$, $\bar{F}_{\tau B^{\prime} W}$ are forces of cohesion friction between contacting wheel surfaces and rail threads i.e. $\bar{F}_{\tau A}=\bar{F}_{f r A}, \bar{F}_{\tau A^{\prime}}$ $=\bar{F}_{m p A^{\prime}}, \quad \bar{F}_{\tau B}=\bar{F}_{f r B}, \bar{F}_{\tau B^{\prime}}=\bar{F}_{f r B^{\prime}}, \bar{F}_{\tau A^{\prime} W}=\bar{F}_{f r A^{\prime} W}, \bar{F}_{\tau B^{\prime} W}=\bar{F}_{f r B^{\prime} W}$. Tangent constituent $\bar{F}_{\tau}$ directed along the surface of rail threads is sliding friction force $\bar{F}_{\tau}=\bar{F}_{f r}$.

Introducing the notion of "shearing" $F_{s h \cdot x}$ and "retaining" $F_{r e \cdot x}$ forces, with allowance made for active and all reactive forces and in case of the impact of fair wind on the wagon we will get [6]:

$$
\begin{gathered}
F_{s h \cdot x}=G_{x}=G \sin \left(\psi_{0,50}\right) ; \\
F_{r e \cdot x}=F_{f r}^{r}=f_{0}\left(G \cos \psi_{0,50}+F_{r w x}^{\prime} \sin \psi_{0,50}\right) .
\end{gathered}
$$

The condition of wagon rolling down the first profile hump section with grades not steeper than $50 \%$ is

$$
F_{\text {sh } \cdot x} \gg F_{r e \cdot x} \text {. }
$$

This implies that the excess of forces $\Delta F_{r, 50}=F_{s h \cdot x}-F_{r e \cdot x}$, emerging on the first profile hump section is the motive power, the power that causes wagon rolling of the given gravity force $G$ at speed $v_{e, 50}(t)$ and acceleration $a_{50}\left(t\right.$ which depends mainly on the angle of rolling down the hump $\psi_{0,50}$ and to some extent on the coefficient of sliding friction of wheel flanges down the rail and also on the state of roller bearings in truck box units. So, in order to ensure wagon movement at the end of the first profile hump section at speed $v_{e, 50}(t)$ lower than the speed of entrance $v_{e w x}(t)$ on the first braking position $\left(1^{\text {st }}\right.$ BP $)$ i.e. $v_{e}(t)<v_{\text {ewx }}(t)$, it is enough to select a rational value as a major geometrical hump parameter.

It is common knowledge that friction forces as resistance forces are always directed oppositely to the relative speed of wagon rolling down the hump. Friction force is a reactive (braking) force. In case of wagon (with cargo and/or without it) rolling down the hump friction force is a retaining force. That is why shunting masters consider this force to be "harmful" due to which the wagon (cut) may not reach the hump design point or, which is even worse, stop in the switching area impeding accelerated breaking up of the train. On the other hand, friction force as retaining force facilitates space-target regulation of cut speeds. This kind of speed regulation should be enough for switching operation and realization of design speeds of cuts at the exit from these positions. It is possible to provide cut approach to the yard braking position $\left(3^{\text {rd }} \mathrm{BP}\right)$ at speed not more than $23.4 \mathrm{~km} / \mathrm{h}(6.5$ $\mathrm{m} / \mathrm{s}$ ). In doing so the cuts should be able to roll up to the design point and the speed of cut collision in the yard shouldn't exceed $5 \mathrm{~km} / \mathrm{h}(1,39 \mathrm{~m} / \mathrm{s})$.

It should be emphasized that while aiming at provision of space-target cut speed regulation it is necessary to slow down the wagon (or cut). At the same time it is necessary to slow down the rotation of wheels making them partially slide along the rail threads and at the expense of the emerging sliding friction between side surfaces of wheels and braking tires of wagon retarders due to the substantial value of compressed air maximum pressure in pneumo-system $(0.75 \mathrm{MPa})$ it is possible to obtain considerable braking force. That is why the "desired" friction force in spite of generally accepted view shouldn't be referred to incidental or "episodic" forces.

In a general case forces of sliding friction of wheels down the rails with rolling $F_{f r}^{f r p}$ during wagon passing the length of hump $\left(1^{\text {st }} \mathrm{BP}, 2^{\text {nd }} \mathrm{BP}\right)$ or yard braking position $\left(3^{\text {rd }} \mathrm{BP}\right)$ on mechanized humps:

$$
F_{f r}^{f r p}=F_{f r}^{f r}+F_{\tau}+F_{f r p},
$$

where $F_{\tau}$ is tangent component of constraint reaction (rail threads), which is equal according to Coulomb law $F_{\tau}$ $=f_{\text {cк }} N$ with allowance made for the fact that $f_{s l}$ is friction coefficient of wheel sliding along rail threads (metal against metal) $f_{s l}=0.15 / 0.25$ ), $N$ is normal component of constraint reaction which is modulo equal to the sum of projections of all active forces on the vertical axis falling on each box unit, $F_{z}$. It should be noted the value of 
$f_{s l}$ also depends on weather conditions;

$F_{f f r}=f_{a f} F_{a f}$ is friction force emerging between lateral surfaces of wheels and retarder braking bars where $f_{a f}=0$, 14/0, 20 is friction coefficient of sliding of wheel lateral surfaces against retarder brake beams [10]. It should be stressed that the value of $f_{a f}$ also depends on the weather conditions; $F_{a f}$-is application force of retarder brake blocks to the wheel lateral surfaces or average load on the wagon axis (normally it is $90,100,140,150 \mathrm{kN}$ depending on the type of a retarder and air pressure) [11]. Here we are to bear in mind that force $F_{a f}$ is equipotent to retarder braking force $F_{b r \cdot f}$, i.e. $f_{a f} F_{a f}=F_{b r . f}$. While solving practical problems it is possible to take $F_{b r \cdot f} \approx 0.1 G_{x}=0.1 G \cos \psi_{0, b}$.

In that way, when a single wagon (or a cut) is within BP, in a general case the speed of the wagon is reduced (i.e. the wagon slows down) at the expense of sliding of skating surface of wheels in combination with their rolling down rail threads and also on account of sliding between wheel lateral surfaces and retarder brake bars. Special reference should be made to the fact that in BP zone because of application of brake bars through the fault of controller of train sorting speed (human factor) there may occur pure wheel sliding against brake bars until complete stopping of the wagon. In this case the value of $F_{\mathrm{Tm}}$ is large as compared to $F_{\tau}\left(i . e . F_{f f r}>F_{\tau}\right)$ and it is possible that $F_{f r}^{p r}=0$.

We rewrite the above expression for the case of wheel sliding against brake blocks with rolling in the form

$$
F_{f r}^{f p r}=F_{f r}^{p r}+f_{s l} N+f_{a f} F_{a f} \text {. }
$$

Here the normal component $N$ of constraint reaction modulo is equal to the sum of projections of all active forces on the vertical axis $F_{z}$, falling on each box unit. In accordance with this statement we form the above ratio in the following way:

$$
F_{f r}^{f p r}=F_{f r}^{p r}+f_{s l}\left[G \cos \psi_{0, b}+F_{r w x}^{\prime} \sin \psi_{0, b}\right]+f_{a f}\left(F_{a f}+F_{r w y}^{\prime}\right),
$$

where $F_{f r}^{f p r}$ is braking force which causes the movement of the wagon (or a cut) with slowdown; $\psi_{0, b}$ is the angle of descend on the braking position of the hump section, rad.

Making allowance for the fact that each truck wheel enters hump the section of braking position consecutively, i.e. lagging in time $\tau$, we rewrite [5] in the form:

$$
\begin{aligned}
F_{f r}^{f p r}= & \left(F_{f r}^{p r}+f_{s l}\left(G \cos \psi_{0, b}+F_{r w \cdot x}^{\prime} \sin \psi_{0, b}\right)+f_{a f}\left(F_{a f}+F_{r w \cdot y}^{\prime}\right)\right) \\
& \times\left(\sigma_{0}(t)+\sigma_{0}\left(t-\tau_{1}\right)+\sigma_{0}\left(t-\tau_{2}\right)+\sigma_{0}\left(t-\tau_{3}\right)\right),
\end{aligned}
$$

where $\sigma_{0}(t), \sigma_{0}\left(t-\tau_{1}\right), \sigma_{0}\left(t-\tau_{2}\right)$ and $\sigma_{0}\left(t-\tau_{3}\right) \sigma_{0}(t), \sigma_{0}\left(t-\tau_{1}\right), \sigma_{0}\left(t-\tau_{2}\right)$ and $\sigma_{0}\left(t-\tau_{3}\right)$ are dimensionless retarded Heaviside functions which make it possible to present time $t_{i}$ as one analytical expressions appropriate under any value of $t$ in the interval $0 \leq t \leq \tau_{i}$, at that $\sigma_{0}\left(t-\tau_{i}\right)=0$ under $\tau_{i}<t ; t$ is running time, s.; $\tau_{1}, \tau_{2}$ and $\tau_{3}$ is the time lag of emerging of friction force while passing braking position by the second wheel of the leading truck $\left(A^{\prime}\right)$, the first $\left(B_{1}^{\prime}\right)$ and the second wheel $\left(B_{2}^{\prime}\right)$ of rear truck as compared with the first wheel of the leading truck (Figure 1), s:

$$
\tau_{1}=\frac{2 l_{t r}}{v} ; \quad \tau_{2}=\frac{2 l_{w}}{v} ; \quad \tau_{3}=\frac{2 l_{w}+2 l_{t r}}{v}
$$

bearing in mind that $l_{t r}$ and $l_{w}$ is the half of the truck and wagon base, $\mathrm{m} ; v$ is speed of entrance of the wagon onto the $1^{\text {st }}$ BP before the dividing switch, m/s (lower than $30.6 \mathrm{~km} / \mathrm{h}(8.5 \mathrm{~m} / \mathrm{s})$ or $23.4 \mathrm{~km} / \mathrm{h}(6.5 \mathrm{~m} / \mathrm{s})$ according to the design of retarders).

Analyzing the results of the previous reasoning we can write that the condition of wagon movement at the hump section braking positions with gradients $7 / 15 \%$ is (q.v. (5))

$$
G \sin \psi_{0, w i}>F_{f r}^{f p r} \text {. }
$$

Nonobservance of this condition (8) may lead to wagon stopping along the length of hump braking positions which may be the case in practice.

The analysis shows that excess of forces $\Delta F_{f p r i}=G \sin \psi_{0, b i}-F_{f r}^{f p r} \quad(i=\mathrm{I}$, II are the numbers of braking positions) emerging at hump section braking positions is the motive power making possible rolling of the wagon of prescribed gravity force $G$ at speed $v_{e b i}(t)$, and acceleration $a_{b i}(t)$. These wagon kinematic parameters mainly depend on the gradient of hump braking positions $\psi_{0, b i}$, retarder braking force $F_{b r f \text {, }}$, friction coefficient $f_{s l}$ of 
sliding wheels against rail threads. It is necessary to ensure the movement of the wagon on hump sections with slowdown up to speed $v_{b}(t)$ (considerably lower than entrance speed $v_{e w x}(t)$, i.e. $v_{e b i}(t) \ll v_{e w x}(t)$. This can be achieved not only by choosing the rational value of gradient $\psi_{0, b}$ as a geometrical hump parameter but also by close controlling of braking force of wagon retarder $F_{b r f .}$. In this case it is possible to ensure the movement of the wagon at speed $v_{e b i}(t)$, which corresponds to acceleration with slowdown $a_{50}(t)$, considerably lower in value than acceleration at the first profile hump section $a_{50}(t)$, i.e. $a_{b I}(t) \ll a_{50}(t)$.

Summing up the notion of friction force it is necessary to note that in addition to some other friction forces there are accidental or the so called "episodical" forces.

1) Friction forces of wheel flanges sliding along lateral sides of thrust rail $F_{f r}^{w y}$. This kind of force appears during wheel rolling down the rail with sliding from the impact of transverse transferring inertia force $I_{e y}$ and projections of aerodynamic resistance force on the lateral surfaces of wagon with cargo $F_{r w y}^{\prime}$. Here it is assumed that wagon wheel flanges located from the side of the thrust rail are completely addressed to the thrust rail by forces $I_{e y}$ and $F_{f r}^{w y}$. According to the rule of reduction of forces these forces [4], are reduced to the wheels of wheel pairs of the leading and rear trucks $A^{\prime}$ (or $B^{\prime}$, i.e. $\bar{R}_{A^{\prime}}=\left\{\bar{R}_{A^{\prime} 1}, \bar{R}_{A^{\prime} 2}\right\}$ and $\bar{R}_{B^{\prime}}=\left\{\bar{R}_{B^{\prime} 1}, \bar{R}_{B^{\prime} 2}\right\}$ (Figure 2)

Figure 2 has the following symbols: $F_{A^{\prime} W}=I_{e y}+F_{r w y}^{\prime}$ is sum of forces $I_{e y}$ and projection of force $F_{r w y}^{\prime}$ onto the transverse axis $y$ (index $W$ means that the forces act in the frontal plane); $F_{A^{\prime} W}^{\prime}=-F_{A^{\prime} W}$ are transverse forces reduced to points $A^{\prime}$ and $B_{1}^{\prime}$ (point $B_{1}^{\prime}$ in Figure 1 is not shown); $M_{W}$ is moment from pair of forces $F_{A^{\prime} W}^{\prime}$ (which is applied in points $A^{\prime}$ and $B_{1}^{\prime}$ ), and $F_{r w y}^{\prime}$ (which is applied to the wagon lateral sides and/or cargo). In what follows the moment from pair of forces $M_{W}$ will not be taken into account because it is not needed for solving the problem in question. It is should be remembered that moment $M_{W}$ is necessary for solving problem on tilting of the wagon with cargo.

Force $F_{f r}^{w y}$ is found according to Coulomb law:

$$
F_{f r}^{w y}=f_{r c \cdot f r}\left(I_{e y}+F_{r w y}^{\prime}\right),
$$

where $f_{r c . f r}$ is reduced coefficient of sliding friction for freight cars (i.e. a symbolic value) [7]

$$
f_{r c \cdot f r}=\frac{F_{z}}{F_{z}+G_{w p}} \frac{r_{b i}}{r_{w}} f \text {. }
$$

Here $F_{z}$ is a projection of all active forces onto the vertical axis falling on each box unit, kN (Figure 2); $G_{\mathrm{wp}}$ is gravity force of wagon wheel pair with account of rotation inertia, $\mathrm{kN} ; f$ is friction coefficient of sliding between contacting surfaces of wheels and rail threads (for freight car it is taken to be 0.25 ); $r_{b i}$ is rolling bearing inner radius in box units, $\mathrm{m}(0.079) ; r_{w}$ is wheel radius, for a freight car it is equal to 0.475 .

2) Friction forces of sliding of wheels (with rolling) down the rail which emerge in winter conditions under the change of air density followed by snow and hoar frost within the limits of switching bundle zone and on sorting tracks. Here it is necessary to bear in mind that according to Coulomb law:

$$
F_{f r}^{c r}=f_{c r} N
$$

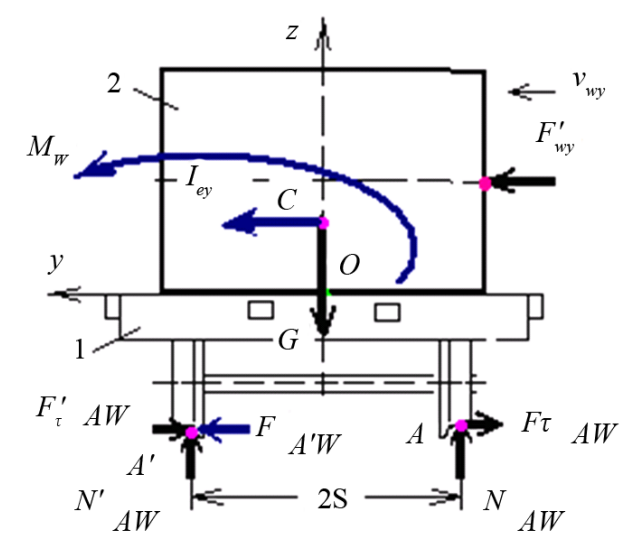

Figure 2. Reduction of force to point $A^{\prime}$ (or $B^{\prime}$ ). 
where $f_{c r}$ is coefficient of resistance of the rail to the wheel movement (it is taken according to full-scale experiment data, or $f_{c r}=f_{s l}$ (cм. (6))), $N=\left\{N_{A}, N_{B}\right\}$ just as before, is a normal component

The condition of wagon movement on this hump section with gradient $0.6 / 2.5 \%$ is also

$$
G \sin \psi_{0 ; 0.6-2.5}>F_{f r}^{c r} .
$$

It follows that excess of forces $\Delta F_{c r}=G \sin \psi_{0 ; 0.6-2.5}-F_{f r}^{c r}$, emerging on hump section with gradients $0.6 / 2.5 \%$, is a motive force ensuring wagon rolling of prescribed gravity force $G$ at speed $v_{e b i: 0.6-2.5}(t)$ and acceleration $a_{b i 0.0-2.2 .5}(t)$ ( $i$ just as previously are the numbers of braking positions). These wagon kinematic parameters mainly depend on the gradient of hump braking positions $\psi_{0, b i ; 0.6-2.5}$ and coefficient of resistance of the rail to the movement of wheels $f_{c r}$. At that the movement of the wagon is with slowdown at speed $v_{e b i ; 0.6-2.5}(t)$ lower than the speed of exit from the braking positions $v_{b i}(t)$, i.e. $v_{e b i 0.6-2.5}(t) \ll v_{e b i}(t)$. This condition can be achieved only by choosing the rational value of tilt angle as a hump geometrical parameter as resistance coefficient of the rail to the wheel movement $f_{c r}$ is an uncontrolled parameter, depending on weather conditions. In this case the wagon moves with slowdown $a_{b i ; 0.6-2.5}(t)$ at speed $v_{e b i, 0.6-2.5}(t)$.

3) Friction force $\bar{F}_{f r \cdot s l}$ under wheel sliding without rolling (with account for momentary impact) resulting from the impact force $\bar{F}_{i f}$ (equipotent to the transverse transferring inertia force $I_{e y}$ ) directed crosswise the wagon (axis $O y$ ) and appearing under striking of wheel pairs at switch points (against switch blades, frogs, guard rails) [2]. Here, we are to bear in mind that force $\bar{F}_{f r \cdot s l}$ is found according to the Coulomb law with allowance made for the sequence of contacting wheel flanges with point switch:

$$
F_{f r \cdot s l}=f_{f r \cdot s l} I_{e y}\left(\sigma_{0}(t)+\sigma_{0}\left(t-\tau_{1 y}\right)+\sigma_{0}\left(t-\tau_{2 y}\right)+\sigma_{0}\left(t-\tau_{3 y}\right)\right),
$$

where $f_{f r s l}$ is coefficient of sliding friction (assumed to be pure sliding) of wheel flanges being struck about against rail threads (for wagon wheels it is taken to be $f_{f r \text { rs }}=0.25$ ); $\sigma_{0}(t), \sigma_{0}\left(t-\tau_{1 y}\right), \sigma_{0}\left(t-\tau_{2 y}\right)$ и $\sigma_{0}\left(t-\tau_{3 y}\right)-f_{\text {сп }}=$ $0.25) ; \sigma_{0}(t), \sigma_{0}\left(t-\tau_{1 y}\right), \sigma_{0}\left(t-\tau_{2 y}\right)$ and $\sigma_{0}\left(t-\tau_{3 y}\right)$ - dimensionless Heaviside retarded functions defined just as in (7a) and differing by the fact that $\tau_{1 y}, \tau_{2 y}$ and $\tau_{3 y}$ is retardation time of emerging friction force while passing point switch of the second wheel of the leading truck $\left(A^{\prime}\right)$, the first wheel $\left(B_{1}^{\prime}\right)$ and the second $\left(B_{2}^{\prime}\right)$ wheel of the rear truck as compared with the first wheel of the leading truck (Figure 2), s.

The condition of wagon movement down point switch is

$$
G \sin \psi_{0, c n}>F_{f r \cdot s l} \text {. }
$$

Analyzing (13), special mention can be made of the fact that excess of forces $\Delta F_{m p}=G \sin \psi_{0, m p}-F_{f r \cdot s l}$, emerging at point switch sections is motive power causing wagon rolling of the designed gravity force $G$ at speed $v_{e \cdot m p}(t)$ and acceleration $a_{m p}(t)$. These kinematic parameters of the wagon depend mainly on the gradient, on which point switch $\psi_{0 \cdot m p}=\psi_{0, b I I}$ is located, and sliding friction coefficient of wheel flanges striking against rail threads $f_{m p}$. At that wagon movement down hump point switches is with slowdown speed $v_{e \cdot m p}(t)$ lower than the speed of wagon entrance onto the zone of switch bundles $v_{e \cdot b \mathrm{II}}(t)$, i.e. $v_{\text {e’mp }}(t) \ll v_{\text {ebbl }}(t)$. This condition can be achieved only by choosing a rational value of tilt angle $\psi_{0, m p}$ as a hump geometrical parameter as sliding friction coefficient of wheel flanges striking against rail threads $f_{m p}$ is an uncontrolled parameter depending on weather conditions. In this case there occurs wagon slowdown with acceleration $a_{m p}(t)$, in value considerably lower than acceleration at section of braking positions with gradients $7 / 15 \% a_{b i, 7-15}(t), 7 / 15 \% a_{b i, 7-15}(t)$, i.e. $a_{m p}(t) \ll a_{b i, 7-15}(t)$.

4) Sliding friction forces $\bar{F}_{f r \cdot b}$ of wheels of the first wheel pair of the wagon leading truck (pure sliding*) in combination with rolling of the rest three wheel pairs of the wagon truck during wagon movement down hump tracks with the help of brake block.

Force $\bar{F}_{f r \cdot b}$ is found according to the formula:

$$
\bar{F}_{f r \cdot b}=F_{f r \cdot b}^{r}+F_{f r}^{s l b},
$$

where $F_{f r}^{r}$ is symbolic sliding friction under pure rolling of wheels and elements in bearings of box units ((4) and (4a)):

$$
F_{f r}^{r}=f_{0}^{\prime}\left(G \cos \psi_{0 ; 1-1.5}+F_{r w x}^{\prime} \sin \psi_{0 ; 1-1.5}\right)
$$


with allowance made for the fact that $f_{0}^{\prime}$ is some symbolic (or reduced) coefficient

$$
f_{0}^{\prime}=\frac{n_{w b} f_{w}}{r_{w}}+\frac{n_{b b} f_{k 0}}{r_{b}} \frac{k}{n_{b} n_{a f}} .
$$

Here $n_{w b}$ is the number of wheels in trucks, item. $\left(n_{w b}=6\right) ; n_{b b}$ is the number of bearings in truck box units, units. $\left(n_{b b}=12\right)$;

$F_{f i}^{s l b}$ is sliding friction force of the first wheel pair of the leading truck (at that one of the wheels is performing sliding with rolling while the other one together with the braking block is performing pure sliding):

$$
F_{f r}^{s l b}=f_{s l b} N_{1},
$$

where $f_{s l b}$ is coefficient of sliding friction of wheels against the rail ("metal against metal")

$f_{\text {slb }}=f_{a f}=0.15, \cdots, 0.25 ; N_{1}=N / n_{w b}$ (here $N=\left\{N_{A}, N_{B}\right\}$ is just as previously, normal component of constraint reaction).

Putting (15) and (16) in (14) we will get:

$$
F_{f r \cdot b}=f_{0}^{\prime}\left(G \cos \psi_{0 ; 1-1.5}+F_{r w x}^{\prime} \sin \psi_{0 ; 1-1.5}\right)+f_{s l b} N_{1},
$$

or, taking into account the fact that $N_{1}=N / n_{w b}$,

$$
F_{f r \cdot b}=\left(f_{0}^{\prime}+\frac{f_{s l b}}{n_{w b}}\right)\left(G \cos \psi_{0 ; 1-1.5}+F_{r w x}^{\prime} \sin \psi_{0 ; 1-1.5}\right) .
$$

Having regard to the fact that sorting yard tracks are designed with easy grades $(1 / 1.5 \%)$, for which $\cos \left(\psi_{0 ; 1-1.5}\right)=1$ and $\sin \left(\psi_{0 ; 1-1.5}\right)=0$,

$$
F_{f r \cdot b}=f_{f r b} G,
$$

where $f_{f r b}$ is coefficient of rolling friction of wheels with sliding in respect to the rail threads together with braking block under the wheels

$$
f_{f r b}=f_{0}^{\prime}+\frac{f_{s l b}}{n_{w b}} .
$$

The condition of wagon movement down sorting yard track with gradients is $1 / 1.5 \%$

$$
G \sin \psi_{0,1-1.5}>F_{f r \cdot b} .
$$

Non-observance of this condition will result in wagon stopping at the prescribed length of the sorting yard track.

Hence it follows that excess of forces $\Delta F_{b}=G \sin \psi_{0 ; 1-1.5}-F_{f r \cdot b}$ emerging at the hump sections with gradients $1 / 1.5 \%$, is the power causing wagon movement with acceleration $a_{1-1.5}$, which is, however, lower in value than acceleration at the sections of switching zone with gradients $1 / 2.5 \%$, i.e. $a_{s s}<a_{1-2.5}$. These kinematic parameters of the wagon mainly depend on the hump profile with gradients $\psi_{0,1-1.5}$ and coefficient of rolling friction of the wheels with sliding against rail threads together with braking block under the wheel $f_{\text {frb }}$. In so doing it is necessary to ensure the movement of the wagon in the hump yard as far as the group of standing wagons with slowdown at speed $v_{e, 1-1.5}\left(t\right.$ lower than the speed of exit of the wagon onto the zone of point switches $v_{e \cdot b s s}(t)$, i.e. $v_{e, 1-1,5}(t) \ll v_{e, b s s}(t)$. These condition can be achieved not only by choosing the rational value of tilt angle $\psi_{0, s s}$, as a hump geometrical parameter, but also by choosing material of contacting surface of the wheel with braking block $f_{f r b}$, as the coefficient of sliding friction of the other wheel of the wheel pair of the leading track against the other rail thread is an uncontrolled parameter. In this case there occurs slowdown of the wagon with acceleration $a_{1-1.5}(t)$, considerably lower in value than acceleration at the sections of point switching with gradients $10 / 12 \%$ $a_{s s}(t)$, i.e. $a_{1-1.5}(t) \ll a_{s s}(t)$.

Summing up the results of the conducted analysis concerning the character of resistance (braking) forces due to which there occurs wagon (or cut) movement with slowdown it can be noted that for ensuring wagon rolling 
down the hump up to the moment of its stopping together with the group of standing wagons it is necessary to fulfill the conditions: $a_{50}(t) \gg a_{b i}(t) ; a_{m i}(t)>a_{w s}(t) ; a_{s w}(t)>a_{s s}(t)$ and $a_{s s}(t)>a_{1-1.5}(t)$, which corresponds to adherence to inequalities $\Delta F_{k, 50} \gg \Delta F_{b p i} ; \Delta F_{b p i}>\Delta F_{w s} ; \Delta F_{w s}>\Delta F_{s s}$ and $\Delta F_{s s}>\Delta F_{b}$ (q.v. (5), (8), (11), (13) and (18)).

Thus, there have been derived analytical formulas for determination of motive forces and resistance (braking) forces affecting the wheels of wheel pairs of the wagon during its rolling down hump longitudinal profile.

\section{Conclusions}

1) On the basis of classical statements of theoretical and applied mechanics, computable models of wagon rolling down the hump have been constructed and identified motive and resistance (braking) forces which will make it possible to model geometrical hump (parameters and kinematic characteristics of wagon movement).

2) Various conditions have been formulated, which makes it possible for a wagon to move down the hump profile elements allowing ensuring wagon (cut) slowdown in the process of movement from the hump crust down the design point of the sorting yard track.

The novelty of the derived analytical formulas of braking forces for each section of hump profile consists in correct account of all types of resistance affecting wagon movement. The obtained results of the research are a new stage in the development of this problem.

The significance of this methodology is presented by the opportunity of constructing a mathematical model of wagon rolling down the hump with allowance made for the influence of aerodynamic resistance due to the speed and direction.

In the long term the obtained results of the research can be used for solving technical problems of determination of hump rational geometrical parameters and wagon kinematic characteristics' during its rolling.

\section{References}

[1] Turanov, Kh.T., Sitnikov, S.A. and Myagkova, A.V. (2011) Mathematical Modeling of Rolling Speed of the Wagon on the First Profile Hump Section. Transport: Science, Technology, Management, 1, 24-29. [In Russian: Математическое моделирование скорости скатывания вагона на первом профильном участке горки. Транспорт: Наука, техника и управление, 2011]

[2] Turanov, Kh.T., Sitnikov, S.A. and Myagkova, A.V. (2011) Mathematical Justification of the Necessity of Location the First Braking Position on the First Profile Hump Section. Transport: Science, Technology, Management, 3, 10-14. [In Russian: Математическое обоснование необходимости расположения на первом профильном участке сортировочной горки первой тормозной позиции Транспорт: Наука, техника и управление, 2011]

[3] Turanov, Kh.T. and Myagkova, A.V. (2011) The Dynamics of Wagon Rolling Down the Hump. Herald of the East-Ukrainian National University, 12, 215-227. [In Ukraine: Динамика скатывания вагона с горки/ Х.Т. Туранов, А.В. Мягкова// ВІСНИК Східноукраінского національного університету, № 10 (152). ЧАСТИНА І. - Луганьск, 2010]

[4] Buchholz, I.M. (1967) Fundamental Course of Theoretical Mechanics. P. I. Kinematics, Statics, Dynamics Material point/ I.M. Buchholz. M: Nauka, 467. [In Russian: Основной курс теоретической механики/ Н.Н. Бухгольц. М.: Наука, 1967]

[5] Loitsyansky, L.G. and Lurje, A.I. (1983) The Course of Theoretical Mechanics, V.II. Dynamics/ M.: Nauka, 640. [In Russian: Курс теоретической механики. Т.2. Динамика. М: Наука. 1983]

[6] Turanov, K. (2014) Analytical Investigation of Wagon Speed and Traversed Distance during Wagon Hump Rolling under the Impact of Gravity Forces and Head Wind/ Khabibulla Turanov//. Global Journal of Researches in Engineering: A. Mechanical and Mechanics Engineering, 14, 1-9.

[7] Turanov. K. (2014) The Dynamics of the Wagon Rolling Down the Hump Profile under the Impact of Fair Wind/ Khabibulla Turanov//. Direct Research Journals of Engineering and Information Technology (DRJEIT), 2, 17-24. http://directresearchpublisher. org/drjet/archive/ 2014/May/pdf/Turanov.pdf

[8] Turanov, Kh.T. (2012) Theoretical Mechanics in Special Tasks on Cargo Transportation: Teaching Aid for Students of Railway Universities. Publishing House of USUPT, Novosibirsk, Nauka, Ekaterinburg, 447. [In Russian: Теоретическая механика в специальных задачах грузовых перевозок: учебное пособие для студентов вузов железнодорожного транспорта. Новосибирск: Наука, Екатеринбург, Изд-тво УрГУПС, 2012]

[9] Pchelin, V.K. (1973) Special Parts of Higher Mathematics, M: The Higher School. 464. [In Russian: Специальные разделы высшей математики/ В.К. Пчелин. М.: Высш. шк., 1973] 
[10] Thekhinform, M. (2003) Regulations and Standards for the Design of Screening Devices on 1520 mm Railway Gauge. 168. [In Russian: Правила и нормы проектирования сортировочных устройств на железных дорогах колеи 1520 мМ. М.: ТЕХИНФОРМ, 2003]

[11] Kobzev, V.A. (2009) Technical Means of Hump Safety. Part 1. The Tutorial, M: MIIT. 92. [In Russian: Технические средства сортировочных горок, обеспечивающие безопасность движения. Часть 1. Учебное пособие/ В.А. Кобзев. - М.: МИИТ, 2009] 